Atıf/Citation: S. İ. BOZKUŞ, N. ŞEN, "2,4,6-Trinitrofenol ve Trinitrotoluen ile 1-Bromopiren Arasında Oluşan Yeni Enerjik Ko-kristalin Karakterizasyonu ve Enerjik Performans Özellikleri”, Süleyman Demirel Üniversitesi Fen Edebiyat Fakültesi Fen Dergisi, 14, 136-149, 2019.

\title{
2,4,6-Trinitrofenol ve Trinitrotoluen ile 1-Bromopiren Arasında Oluşan Yeni Enerjik Ko-kristalin Karakterizasyonu ve Enerjik Performans Özellikleri
}

\author{
Sinecan İrem BOZKUŞ ${ }^{1}$, Nilgün ŞEN *1,2 \\ ${ }^{1}$ Polis Akademisi, Adli Bilimler Enstitüsü, Ankara, Türkiye \\ ${ }^{2}$ Edinburgh Üniversitesi Kimya Fakültesi, EH9 3FJ, Edinburgh, Birleşik Krallı
}

*yazışılan yazar e-posta: nilgunsen2001@gmail.com; nilgun.sen@ed.ac.uk; nilgun.sen@pa.edu.tr

(Alınış / Received: 09.03.2019, Kabul / Accepted: 14.05.2019, Yayımlanma / Published: 31.05.2019)

Özet: Ko-kristallendirme, 1:1 molar oranda Pikrik asit ile 1-Bromopiren ve TNT ile 1Bromopiren arasında çözücü buharlaştırma yöntemiyle hazırlandı ve ko-kristallerin yapısı tek kristal ve toz X-Işını kırınımı, Kütle spektrometresi, Kızılötesi spektroskopisi ile karakterize edildi. Kırınım verileri analizi, ko-kristallerin öncelikle elektron verici-elektron alıcı $\pi \ldots \pi$ istifleme etkileşimlerinden oluştuğunu ortaya koydu. Darbe hassasiyeti testleri sonucu yapılan ölçümler ile TNT: 1-Bromopiren ve Pikrik Asit: 1-Bromopiren ko-kristalleri, saf TNT, Pikrik Asit 'e kıyasla önemli ölçüde azaltılmış darbe duyarlılığını göstermiştir. Elde edilen yeni enerjik ko-kristaller detaylı çalışması ile yoğunluk, oksijen dengesi, erime noktası, ayrışma sıcaklı̆̆ı, patlama performansı (hız, basınç) gibi önemli fiziksel ve kimyasal özelliklerin değiştiğini ortaya koymaktadır. Ko-kristalizasyon çalışması ile yeni keşfedilen alternatif enerjik maddelerin iyileştirilmiş özelliğe sahip olduğunu ve mevcut enerjik materyalin fiziksel ve kimyasal özelliklerini değiştirmenin etkili bir yöntem olduğunu vurgulamaktadır.

Anahtar kelimeler: Enerjik madde, 2,4,6-Trinitrofenol, Trinitrotoluen, Ko-kristallenme, Patlayıc1 Hassasiyeti, Patlayıc1 Performansı.

\section{Characterization and Energetic Performance Properties of New Energetic Co- crystals formed between 2, 4, 6-Trinitrophenol, Trinitrotoluene and 1- Bromopyrene}

\begin{abstract}
A 1:1 co-crystals of Picric Acid with 1-Bromopyrene and TNT with 1-Bromopyrene were prepared by a solvent evaporation method, and the structure of the co-crystals were determined by single-crystal and powder X-ray diffraction, Mass spectrometry, Infrared spectroscopy techniques. The diffraction data analysis revealed that the co-crystals are primarily formed through donor-acceptor $\pi . . . \pi$ stacking interactions. The TNT:1-Bromopyrene and Picric Acid:1-Bromopyrene co-crystals indicates significantly reduced impact sensitivity relative to pure TNT, Picric Acid. A detailed study of the cocrystals formed reveals a modification of crucial properties including density, oxygen balance, melting point, decomposition temperature detonation performance (velocity, pressure). The acquired results highlight that cocrystallization provides the newly discovered energetic material with attractive properties, and is an effective way to alter existing energetic material.
\end{abstract}

Keywords: Energetic material, 2, 4, 6-Trinitrophenol, Trinitrotoluene, Co-crystallisation, Explosive sensitivity, Explosive performance 


\section{Giriş}

Enerjik maddeler hem askeri hem de sivil kullanımları olan (madencilik, taş ocağı, uzay araştırmaları ve havai fişekler) dışardan oksijen almaya ihtiyaç duymadan hızlı yanma reaksiyonuna uğrayarak yüksek 1sı ve basınç açığa çıkaran maddelerdir [1-6]. Sahip oldukları yüksek enerji içerikleri sebebiyle infilak ettiklerinde çevrelerinde yıkıma ve hasara sebep olurlar. Bu maddelerin tepkimeleri termal, mekanik veya elektrostatik ateşleme kaynakları kullanılarak başlatılabilir. Enerjik materyallerde patlama tepkimesinin devam etmesi için ayrıca bir oksijen kaynağına gerek duyulmamaktadır [7]. Bu materyallere uzun süreli depolama, yüksek sıcaklık, şarapnel etkisi, mekanik şok ve sürtünme etkisi gibi çevresel etkilerden oldukça fazla etkilendiğinden tekrar üretilebilirlik ve güvenilirlik gibi özellikler önem yaratmaktadır. Özellikle yasal sınırlar içerisinde kullanımları esnasında herhangi bir kaza ve olumsuzluk yaşanmaması için yüksek enerjili maddeler üzerinde iyileştirme çalışmaları yapılmaktadır. Sivil ve askeri amaçlı patlayıcı madde uygulamalarında geliştirilen/kullanılan maddenin yüksek enerjik özelliklere sahip olurken hassasiyetinin de düşük olması; yani sürtünme, şok, 1sı gibi istenmeyen dış etkilere maruz kaldığında kolayca infilak etmemesi amaçlanmaktadır. Bu sebeple iyi bir patlayıcı madde yüksek enerji ve yoğunluğa, termal olarak kararlı bir yapıya; düşük hassasiyete sahip olmalıdır [8-9]. Yeni nesil hassasiyeti düşük enerjik materyaller tasarlanırken performansın belirlenmesinde bu özelliklerin bilinmesi oldukça önemlidir.

Enerjik maddeler üzerine yapılan literatür araştırmalarında patlayıcı maddenin performansını (yoğunluk, patlama hızı ve patlama basınc1) arttırmak için organik yapılı maddelerde hidrojen atomu veya hidroksil grupları yerine daha ağır olan azot $(\mathrm{N})$ veya nitro $\left(-\mathrm{NO}_{2}\right)$ grupları eklenmesi sıklıkla başvurulan yöntemlerdir. Yine moleküler hacmi azaltan ve oluşma enerjisini artıran halkalı yapılar da kullanılmaktadır. Ancak performansı artırmak için yapılan bu düzenlemeler yapının hassasiyetini arttırabilmektedir. Hassasiyetin artmasını engellemek için nitro gruplarının yerine nitrozo (-NO) veya amin (- $\left.\mathrm{NH}_{2}\right)$ grupları kullanılmaktadır. Bunun yanında maddeye performansını belirgin oranda azaltmayacak kompleksler, bağlayıcı ve kaplamalar da eklenmektedir. Klasik veya yeni geliştirilen patlayıcı maddeler üzerinde yapılan tüm bu değişimler yoğunluk, oluşma entalpisi gibi performans özelliklerini arttırmak ve hassasiyetini azaltmak içindir. Bunun yanında geliştirilen yeni maddenin kullanım sonrası çevreye en az zararı vermesi de dikkat edilen bir başka husustur [8-11]. Yüksek enerjili maddelerin performans özelliklerini arttırmak ve hassasiyetlerini azaltmak için son yıllarda uygulanan yöntemlerden birisi de ko-kristal oluşturma yöntemidir. Kokristallenme, bir kristal kafes içinde belirli bir oranda iki veya daha fazla nötr moleküler bileşenden oluşan yeni bir kristalin oluşmasıdır [12]. Farmasötik alanda sıklıkla kullanılan bu yöntemde enerjik maddenin ikinci bir kimyasal madde ile genellikle moleküller arası etkileşimler ile kristal oluşturması sağlanır. Ko-kristallerde ko-kristali meydana getiren bileşenler hidrojen bağları, halojen bağları, $\pi-\pi$ etkileşimleri gibi farklı moleküller arası etkileşimler ile bir araya getirilmektedir [12]. Bu moleküller arası etkileşimleri anlamak, ko-kristalin ortaya çıkma şartlarının sağlanması için oldukça önemli bir etkendir. Hidrojen bağı, en güçlü moleküller arası etkileşimlerden biridir ve ko-kristal tasarımında önemli etkenlerden biridir. Hidrojen bağının gücü ve yönelimi, ko-kristalin tasarlanmasını daha avantajlı hale getirmektedir [13-14]. Bir diğer önemli güçlü moleküller arası etkileşim ise halojen bağıdır. Halojen bağı, bir nükleofil atom ile bir halojen atomun arasındaki pozitif elektron deliği ile ( $\sigma$ boşluğu) arasındaki moleküller arası etkileşimdir [15]. Halojen bağının ortaya çıkması, bu pozitif elektron boşluğuyla etkileşimine bağlı olduğundan, halojen bağ 1 da hidrojen bağ gibi, çok yönlüdür [16]. Benzen halkaları arasındaki moleküler etkileşimler olan, $\pi$-etkileşimleri de ko-kristallenme açısından önemli etkileşimlerden biridir. Homojen yapıda bir sistemde gözlenen etkileşimler genellikle kenarlardan yüzeye doğrudur veya 
elektrostatik etkileşim en üst düzeye çıktığından kaymıştır [17]. Aromatik halkalardaki $\pi$ elektron yoğunluğuna bağlı olarak, her iki aromatik yüzün üzerinde bulunan kısmi negatif yük yoğunluğu ve kenarlarda bulunan kısmi pozitif yük yoğunluğu dört kutuplu bir alan ortaya çıkarmaktadır. Meydana gelen bu çekim alanı yüzey merkezli paralel istifleme veya kenar merkezli paralel istifleme oluşturmaktadır. Bu etkileşimler de " $\pi$ istifleme" ve " $\pi-\pi$ etkileşimleri" olarak adlandırılmaktadır [7].

Literatürde, TNT ile yapılan ilk ko-kristal TNT: piren kristalidir, Bu çalışmada sadece ko-kristalin tek kırınım sonuçları incelenmiştir [18]. CL-20 ile TNT arasında oluşturulan ko-kristal, CL-20 maddesinin performans etkisini azaltmamakla birlikte hassasiyetini belirgin oranda azaltmıştır [19]. Ko-kristal yapıları oluşturan iki maddeyi bir arada tutan kuvvetlerin kimyasal reaksiyon sonucu oluşan bağlardan ziyade hidrojen bağları veya Van Der Waals kuvvetleri gibi etkileşimler olduğu yapılan çalışmalarda ortaya konulmuştur [20-22].

$\mathrm{Bu}$ çalışmada enerjik madde olan Pikrik asit ve TNT, 1-Bromopiren ile kokristallendirildi. Tek kristal ve Toz ve tek X-Işını Kırınımı (XRD) , kütle spektrometresi, ${ }^{1} \mathrm{H}-\mathrm{NMR}$, infrared (IR) spektroskopisi kullanılarak elde edilen maddeler karakterize edildi. Optik mikroskop ile elde edilen maddeler morfolojik olarak incelendi. Bunun yanında ko-kristallerin 1sısal davranışlarını gözlemlemek için kalorimetrik yöntemler ile erime ve bozunma sıcaklıkları ölçüldü. BAM düşme çekiç cihazı kullanılarak ko-kristallerin hassasiyeti ölçüldü. Ayrıca Gaussian 09 programıyla yapılan hesaplamayla maddelerin oluşum entalpileri $\left(\Delta \mathrm{H}^{\circ} \mathrm{f}\right)$, Kamlet-Jacobs denklemleri ile patlayıcı hızı ve basıncı hesaplandı. Bu çalışma sonucunda savunma sanayi, askeri alanda veya endüstride kullanılmak üzere fiziksel ve kimyasal özellikleri iyileştirilmiş, daha güvenli ve depolamada sorun yaşanmayan alternatif olarak gelecekte kullanılabilecek enerjik malzemeler elde edildi.

\section{Materyal ve Metot}

\subsection{Materyal}

2,4,6-Trinitrofenol (Pikrik Asit) (su ile nemlendirilmiş, $\geq 98 \%$ ), 1-Bromopiren (\%94) ve 2,4-dinitrotoluen (\%97) Sigma-Aldrich' ten satın alındı. Trinitrotoluen (TNT), literatürde bilinen yönteme göre 2,4-dinitrotoluen'den (DNT) sentezlendi [23] ve ${ }^{1} \mathrm{H}$ NMR ile karakterize edildi (Şekil E1). Maddelerin açık formülleri Şekil 1'de görülmektedir.<smiles>Cc1c([N+](=O)[O-])cc([N+](=O)[O-])cc1[N+](=O)[O-]</smiles>

TNT<smiles>O=[N+]([O-])c1cc([N+](=O)[O-])c(O)c([N+](=O)[O-])c1</smiles>

Pikrik Asit<smiles>Brc1ccc2ccc3cccc4ccc1c2c34</smiles>

1-Bromopiren

Şekil 1. Maddelerin açık formülleri

\subsection{Numune Hazırlama Metodu}

Ko-kristallendirme, 1:1 molar oranda Pikrik asit $(1.57 \mathrm{mg})$, TNT (1.55 mg) ve 1Bromopiren (1.92 mg) \% 85'lik metanol-su karışımında (yaklaşık 3-5 mL), $50{ }^{\circ} \mathrm{C}$ 'de maddelerin çözündürülmesi ve 45 dakika boyunca karıştırılmasıyla gerçekleştirildi. 
Çözücü birkaç gün boyunca oda sıcaklığında buharlaştırıldı. Ko-kristallenme sonucu oluşan Pikrik asit:1-Bromopiren (PIC: BRP)'nın iğne kırmızı renkli kristalleri ve TNT:1-Bromopiren (TNT: BRP)'nin iğne sarı renkli kristalleri elde edilmiş ve Şekil 2 'de gösterilmiştir.

\subsection{Optik Mikroskop}

Pikrik asit, TNT, PIC: BRP ve TNT: BRP kristallerinin optik mikroskop görüntüleri SK2005A polarizasyon mikroskobu kullanılarak alındı.

\subsection{Toz X-ışını Kırınımı (PXRD)}

PXRD verileri, $\mathrm{Cu}-\mathrm{Ka}$ radyasyonu $(\lambda=1.54439 \AA)$ ve sirasiyla $40 \mathrm{kV}$ ve $40 \mathrm{~mA}$ çalışma voltajı ile Bruker D2 PHASER cihazı kullanılarak kaydedildi. Veriler $2 \theta=5-$ $50^{\circ}$ açı aralığında toplandı. $\mathrm{Bu}$ yöntem ile oluşan yeni ko-kristallerin başlangıç maddeleri ile karşılaştırılması yapılmıştır.

\subsection{Tek Kristal X- ışını Kırınımı}

Ko-kristalin tek kristal X ışını kırınım verileri, bir Oxford Cryo sistemi ile donatılmış Agilent Technologies Süper Nova difraktometresinde toplandi. Veri toplama sirasinda kristal sicaklık $\mathrm{T}=173.15 \mathrm{~K}$ 'de tutuldu. Olex2 program1 [24] kullanılarak, Intrinsic Phasing Solution yöntemi kullanılarak ShelXT [25] yapı çözümü programı ile çözülmüştür. Model, En Küçük Kareler minimizasyonu kullanılarak ShelXL [26] 2017/1 versiyonuyla geliştirildi.

\subsection{Kızılötesi (IR) Spektroskopisi}

IR spektrumları, ATR ekipmanlı Perkin-Elmer Spektrumu 65 FT-IR spektrometresi ile Fourier dönüşüm teknikleriyle elde edildi. Her spektrum $4000-400 \mathrm{~cm}^{-1}$ aralığında, çözünürlük oran $14 \mathrm{~cm}^{-1}$ tarandı.

\subsection{Diferansiyel Taramalı Kalorimetre (DSC)}

DSC analizi NETZSCH STA 449 F1 Diferansiyel Taramalı Kalorimetre cihazı kullanılarak gerçekleştirildi. $1.56 \mathrm{mg}$ numune alüminyum krozeye yerleştirildi ve numunelerin 1 sıl davranış1, 25-400 ${ }^{\circ} \mathrm{C}$ aralığında $10{ }^{\circ} \mathrm{C} / \mathrm{dk}^{\prime}$ lık bir 1 sıtma hızında azot gazı kullanılarak $(30.0 \mathrm{~mL} / \mathrm{dk})$ gerçekleştirildi.

\subsection{Kütle Spektrometresi (MS)}

Maddelerin kütle spektrumları, doğrudan giriş (DI) ünitesi ile donatılmış Shimadzu 2010 Plus ile elde edildi. DI sicaklığı 35 ile $110^{\circ} \mathrm{C}$ ve iyonizasyon 70 elektron volt $(\mathrm{eV})$ elektron ile sağlandı. 5 ile 10 dakika arasında iyonlaşma aralığı boyunca, $\mathrm{m} / \mathrm{z}$ (kütle/yük) değerleri için 10 nokta seçildi ve okuldu. PIC: BRP ve TNT: BRP kokristalleri için elde edilen kütle spektrumları Şekil E2 ve Şekil E3 gösterilmiştir. Şekil E2'de PIC: BRP için temel pik $\mathrm{m} / \mathrm{z}=282$ ve $\mathrm{m} / \mathrm{z}=280,229,201$ izotop piklerine rastlanmıştır. Şekil E3'de TNT: BRP için temel pik $\mathrm{m} / \mathrm{z}=282$ ve $\mathrm{m} / \mathrm{z}=280,83,48$ izotop piklerine rastlanmıştır.

\subsection{Darbe Duyarlılı̆̆ı (Hassasiyet) Testi}


Darbe hassasiyeti BAM düşme çekiç cihazı (BFH-12) kullanılarak belirlendi. Pikrik asit, TNT, PIC: BRP ve TNT: BRP için hassasiyet testi Cambridge Üniversitesi Cavendish Laboratuarında gerçekleştirildi. İki koaksiyel çelik silindirden oluşan örs tertibatına $40 \mathrm{~mm}^{3}$ lük bir örnek alındı. Örs cihazları testten sonra numuneyle birlikte atıldı. $10 \mathrm{~cm}$ 'den $100 \mathrm{~cm}$ 'ye kadar olan yüksekliklerden numuneye $10 \mathrm{~kg}$ 'lık bir yük yerleştirildi. Test edilen her iki numune için de sinırlayıcı etki enerjisi elde etmek için "altıda bir" test, 30 deneme Bruceton yöntemi uygulandı [27-28]. Darbe hassasiyeti $($ Enerji=mgh $(\mathrm{J}))$ potansiyel enerji formülü kullanılarak hesaplandı.

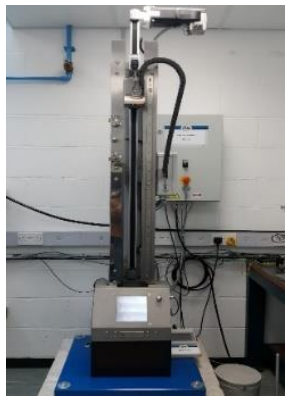

(a)

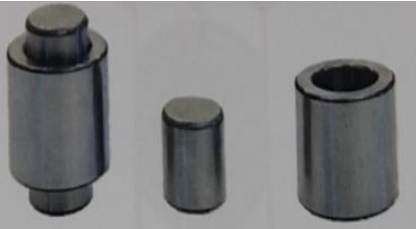

(b)

Şekil 2. (a) BAM düşme çekiç cihazı, (b) Halka içindeki iki koaksiyel çelik silindirden oluşan darbe cihazı darbe tertibatı

\subsection{Teorik Hesaplamalar}

Bu çalışmada, tüm ab initio hesaplamaları Gaussian 09 (Revision-D.01) [29] program paketi kullanılarak yapıldı ve GaussView 5.0.9 [30] tarafindan görselleştirildi. Oluşumların enerjisini ve bileşiklerin patlama parametrelerini hesaplamak için, entalpiler $(\mathrm{H})$, atomize enerji yöntemine göre hesaplandı (Denklem (1); Tablo 1) [3133], tüm temel set Gaussian programına dâhil olan (CBS-4M) yöntemine dayanarak hesaplandı. Yap1 optimizasyonları DFT-B3LYP metodu ile 6-31G (d, p) esaslı gaz fazında yapıldı. Tüm hesaplamalarda girdi dosyası olarak X-1şını verileri kullanıldı. Optimize edilmiş yapıların stabilizasyonu, aynı teori düzeyinde hesaplanan moleküllerin molar hacimleri ve frekans analizi ile görüntü frekansları (NIMAG) sayısı ile kontrol edildi. Denklem (1)'de $\Delta_{\mathrm{f}} \mathrm{H}^{\circ}{ }_{\mathrm{g}, \mathrm{M})}$ molekülün oluşumunun gaz fazı entalpisini, $\mathrm{H}_{(\mathrm{M})}$, molekül M'nin hesaplanan entalpi CBS-4M'yi $\left(\mathrm{H}_{298}\right.$, Tablo 1) temsil eder. $\Sigma_{\text {atoms }} \mathrm{H}^{\circ}$ atomları, atomlar için CBS-4 M ile hesaplanan entalpileri belirtir $\left(1 \mathrm{a} . \mathrm{u}=2623.7 \mathrm{~kJ} \mathrm{~mol}^{-}\right.$ ${ }^{1}$ ). Literatürde belirtilen deneysel oluşum entalpileri $\mathrm{H}, \mathrm{C}, \mathrm{N}, \mathrm{O}, \mathrm{Br}$ atomları için sirasiyla, 52.103, 171.290, 112.970, 59.560 ve 26.740 kcal.mol- ${ }^{1}{ }^{\prime}$ dir [34]. Pikrik Asit, TNT, 1-Bromopiren, TNT: BRP ve PIC: BRP'nin bileşikleri için hesaplanan molar entalpileri Tablo 1'da gösterilmiştir.

$$
\Delta \mathrm{f} \mathrm{H}^{\circ}(\mathrm{g}, \mathrm{M})=\mathrm{H}_{(\mathrm{M})}-\Sigma_{\text {atoms }} \mathrm{H}^{\circ}+\Sigma_{\text {atoms }} \Delta \mathrm{fH}^{\circ}
$$

Tablo 1. CBS-4M Sonuçları

\begin{tabular}{|c|c|c|c|}
\hline Maddeler & p.g. ${ }^{a}$ & NIMAG & -H298/a.u. ${ }^{\mathrm{c}}$ \\
\hline PIC:BRP & $C 1$ & 0 & $\begin{array}{c}- \\
4106710066\end{array}$ \\
\hline TNT:BRP & $C l$ & 0 & $\begin{array}{c}4106.710966 \\
- \\
4070.798014\end{array}$ \\
\hline $\mathrm{H}$ & & 0 & 0.500991 \\
\hline $\mathrm{C}$ & & 0 & 37.786156 \\
\hline $\mathrm{N}$ & & 0 & 54.522462 \\
\hline $\mathrm{O}$ & & 0 & 74.991202 \\
\hline $\mathrm{Br}$ & & 0 & 2572.629704 \\
\hline
\end{tabular}




\section{Bulgular}

\subsection{Ko-kristallerin Mikroskobik Görüntüsü}

Maddelerin kristal morfolojileri, Şekil 3'de gösterilmiştir. Şekil 3 (b)'de görüldüğü gibi, PIC:BRP homojen, kırmızı iğne şeklindeki ko-kristaller sarı bir plaka morfolojisi sergileyen, Şekil 3 (a)' daki Pikrik asidin kristal şeklinden tamamen farklıdır. Şekil 1 (d) 'de görünen sarı renkli, iğne seklindeki TNT:BRP ko-kristalleri, Şekil 3(c)'deki beyaz renkli TNT kristallerinden fiziksel olarak farklı yapıda olduğu görülmektedir. Oluşan ko-kristaller morfolojik olarak Pikrik asit, TNT kristal yapılarından farklı olduğu ve yeni bir madde sentezlendiği Şekil 3'de açıkça görülmektedir.

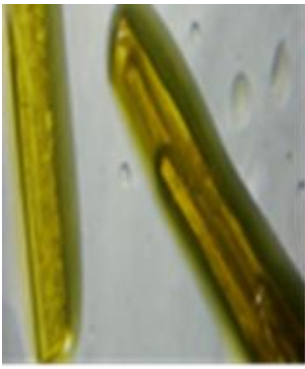

(a)

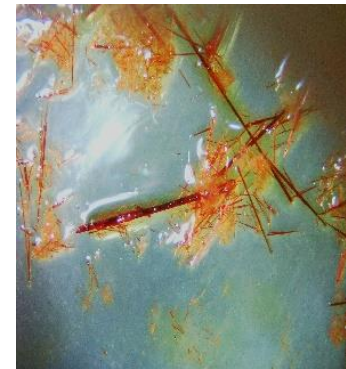

(b)

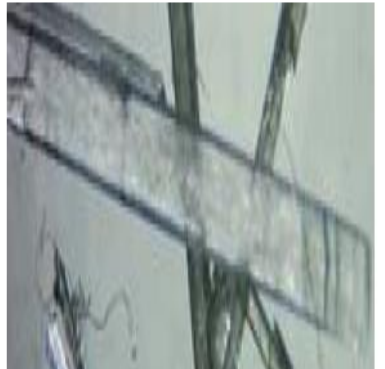

(c)

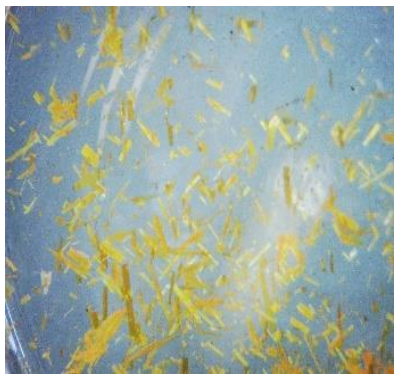

(d)

Şekil 3. (a) Pikrik asit, (b) PIC:BRP, (c) TNT ve (d) TNT:BRP kristallerinin optik mikroskop görüntüleri

\subsection{PIC: BRP ve TNT: BRP Ko-Kristallerinin Yapu Analizi}

Pikrik asit, TNT, 1-Bromopiren, PIC: BRP ve TNT: BRP'nin toz X 1şını kırınımı (PXRD) verileri Şekil 4'de gösterilmiştir. Pikrik asit, TNT ve 1-Bromopiren'nin kırınım pikleri PIC: BRP ve TNT: BRP ko-kristallerinin kırınım piklerinden tamamıla farklı olduğu ve yeni bir malzemenin oluştuğu Şekil 4'de açıkça görülmektedir. PIC: BRP ve TNT: BRP ko-kristallerinde X-1şınları difraksiyonu ile bulunan kristallografik veriler Tablo 2'de gösterilmiştir. Ko-kristal oluşumu $\pi$-istiflemesi ve halojen bağ sonucu oluşmuştur. TNT, Pikrik asidin elektron bakımından zayıf aromatik $\pi$ sistemi ile elektron bakımından zengin aromatik $\pi$ sistemine sahip 1-Bromopiren arasında kovalent olmayan etkileşim meydana gelmiştir. TNT, Pikrik asit aromatik halkasının merkez noktası ile 1-Bromopiren aromatik halkasının merkez noktası arasındaki mesafe 3.663 ve $3.321 \AA$ olarak Mercury programı yardımıyla ölçülmüştür. Bu değer " $\pi-\pi$ etkileşimi" için literatürde verilen değerlerle uyum halindedir $(<4.00 \AA \AA)$ [35]. Kokristalizasyon oluşumunda moleküller arası ve molekül içi etkileşimler görülmektedir. Gerçekte bir tane kuvvetli hidrojen bağı vardır, bu hidrojen bağı Pikrik asidin fenolik grubuyla komşu nitro grubu oksijeni arasında meydana gelen molekül içi (intramoleküler) hidrojen bağıdır (Şekil 5). Ko-kristal oluşumu tamamen " $\pi-\pi$ istifleme" nin bir sonucudur. 1-Bromopiren halkasinın $\pi$ elektron bulutu Pikrik asit, TNT halkasının ortasında bulunan boşluğa doğru delokalize olmuş ve iki halka birleşmiştir. Nitro gruplarının elektron çekici etkisiyle Pikrik asit, TNT halkalarının $\pi$ sistemi deformasyona uğramış ve Pikrik asit, TNT halkalarının ortasında bir elektron boşluğu oluşmaktadır, bu boşluğu 1-Bromopiren halkasının $\pi$ elektronları bir miktar doldurmaktadır, yük aktarma kompleksi meydana gelmiştir. Hazırlanan komplekslerin Kütle ve IR spektrumları da bunu kanıtlamaktadır. 


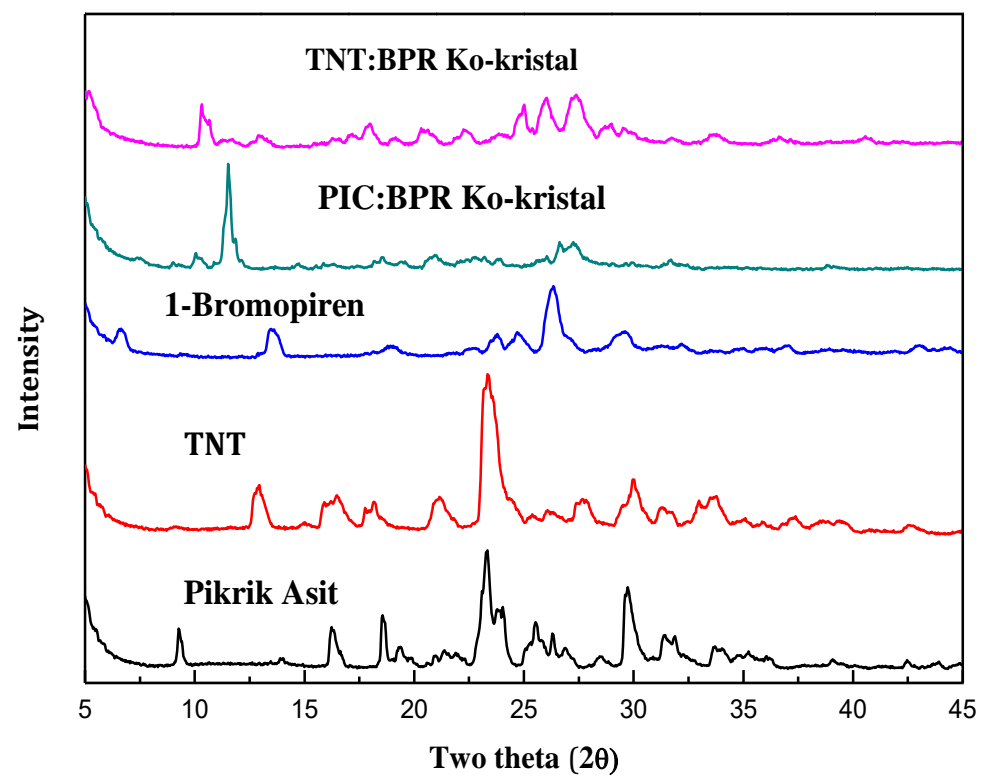

Şekil 4. PXRD desenlerinin Pikrik asit, TNT, 1-Bromopiren, PIC: BRP ve TNT: BRP ile karşılaştırılması

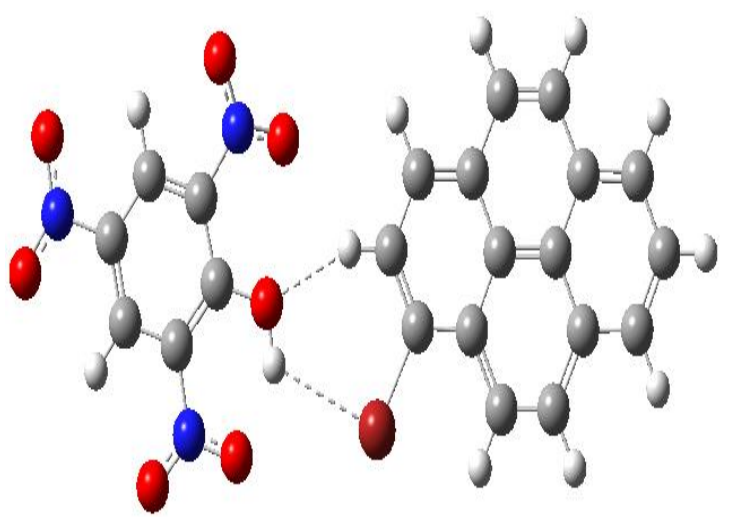

(a)

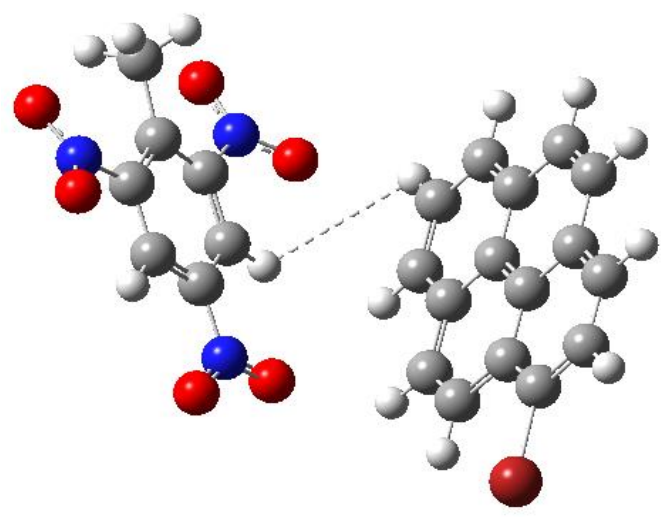

(b)

Şekil 5. (a) Pikrik Asit ve 1-Bromopiren, (b) TNT ve 1-Bromopiren arasında moleküller arası etkileşimler

Tablo 2. TNT: BRP ve PIC: BRP' nin Kristalografik Verileri

\begin{tabular}{|c|c|c|}
\hline & TNT:BRP & PIC:BRP \\
\hline Kimyasal Formül & $\mathrm{C}_{23} \mathrm{H}_{14} \mathrm{~N}_{3} \mathrm{O}_{6} \mathrm{Br}$ & $\mathrm{C}_{22} \mathrm{H}_{12} \mathrm{~N}_{3} \mathrm{O}_{7} \mathrm{Br}$ \\
\hline Molekül Ağırlığı (a.k.b.) & 508.282 & 510.25 \\
\hline Sicaklik/K & $293(2)$ & $293(2)$ \\
\hline Kristal Sistemi & monoklinik & monoklinik \\
\hline Uzay Grubu & $\mathrm{P} 2_{1}$ & $\mathrm{P} 21 / \mathrm{n}$ \\
\hline $\mathrm{a} / \AA$ & $8.049(2)$ & $6.6695(8)$ \\
\hline $\mathrm{b} / \AA$ & $7.0918(13)$ & $16.177(3)$ \\
\hline $\mathrm{c} / \AA \AA$ & $34.378(9)$ & $17.916(3)$ \\
\hline$\alpha /^{\circ}$ & 90 & 90 \\
\hline$\beta /{ }^{\circ}$ & $95.50(2)$ & $96.076(14)$ \\
\hline$\gamma /{ }^{\circ}$ & 90 & 90 \\
\hline Birim Hücre Hacmi $\left(\AA^{3)}\right.$ & $1953.3(8)$ & $1922.1(5)$ \\
\hline $\begin{array}{c}\text { Birim Hücredeki Molekül } \\
\text { Sayı1 (Z) }\end{array}$ & 4 & 4 \\
\hline $\begin{array}{l}\text { Hesaplanan Yoğunluk ( } \rho_{\text {calc, }} \\
\left.\mathrm{g} / \mathrm{cm}^{3}\right)\end{array}$ & 1.735 & 1.763 \\
\hline $\begin{array}{l}\text { Çizgisel Soğurma Katsayısı } \\
\qquad\left(\mu / \mathrm{mm}^{-1)}\right.\end{array}$ & 2.179 & 2.215 \\
\hline $\mathrm{F}(000)$ & 1020 & 1020 \\
\hline Kullanılan Işıma/Dalgaboyu & $\operatorname{MoK} \alpha(\lambda=0.71073)$ & $\operatorname{MoK} \alpha(\lambda=0.71073)$ \\
\hline
\end{tabular}


( $)$

$2 \theta$ Veri Toplama Aralı̆̆ $1{ }^{\circ}$

$$
\begin{gathered}
5.866-59.158 \\
-11 \leq \mathrm{h} \leq 10,-8 \leq \mathrm{k} \leq 9,-46 \\
\leq 1 \leq 46 \\
15168
\end{gathered}
$$

$$
\text { h, k, } 1 \text { Aralığ } 1
$$

Toplam Yansıma Sayıs1

Bağımsız Yansıma Sayısı

Yansıma/ Sinırlama/ Parametre

Sayıları

$\operatorname{GooF}\left(\mathrm{F}^{2)}\right.$

$8347\left[\mathrm{R}_{\text {int }}=0.1358, \mathrm{R}_{\text {sigma }}=\right.$ 0.2578]

$4888[$ Rint $=0.1043$, Rsigma $=$

$8347 / 1 / 229$

$4888 / 0 / 141$

$$
1.744
$$

3.142

Son R indisi $[\mathrm{I}>=2 \sigma(\mathrm{I})]$

$\mathrm{R}$ indisi (tüm yansımalar için) $\Delta \rho \min / \Delta \rho \max \mathrm{e} / \AA^{-3}$

$\mathrm{R}_{1}=0.2186, \mathrm{wR}_{2}=0.4404$

$\mathrm{R}_{1}=0.2956, \mathrm{wR}_{2}=0.4907$ $4.36 /-2.45$

$\mathrm{R}_{1}=0.3360, \mathrm{wR}_{2}=0.6174$

$\mathrm{R}_{1}=0.4284, \mathrm{wR}_{2}=0.6443$

$3.65 /-1.05$

\subsection{Kozılötesi Spektroskopisi}

IR spektrumlarında beklenen fakat gözlenmeyen tek sinyal Pikrik asidin $v_{\mathrm{O}-\mathrm{H}}$ esneme titreşimidir. $\mathrm{Bu}$ sinyal PIC: BRP molekülünün IR spektrumunda $\left(3400-3500 \mathrm{~cm}^{-1}\right)$ gözlenmiyor. Kuvvetli hidrojen bağı IR spektrumlarında beklenen yerde gözlenmeyebilir, zaman zaman $1000 \mathrm{~cm}^{-1}$ kadar düşük enerjiye kayabilir ve beklendiği şiddette gözlenmez [36]. Bu sinyal dişında dikkat edilirse Pikrik Asit, 1-Bromopiren, TNT'nin gözlenen tüm sinyalleri ko-kristalin IR spektrumunda vardır.

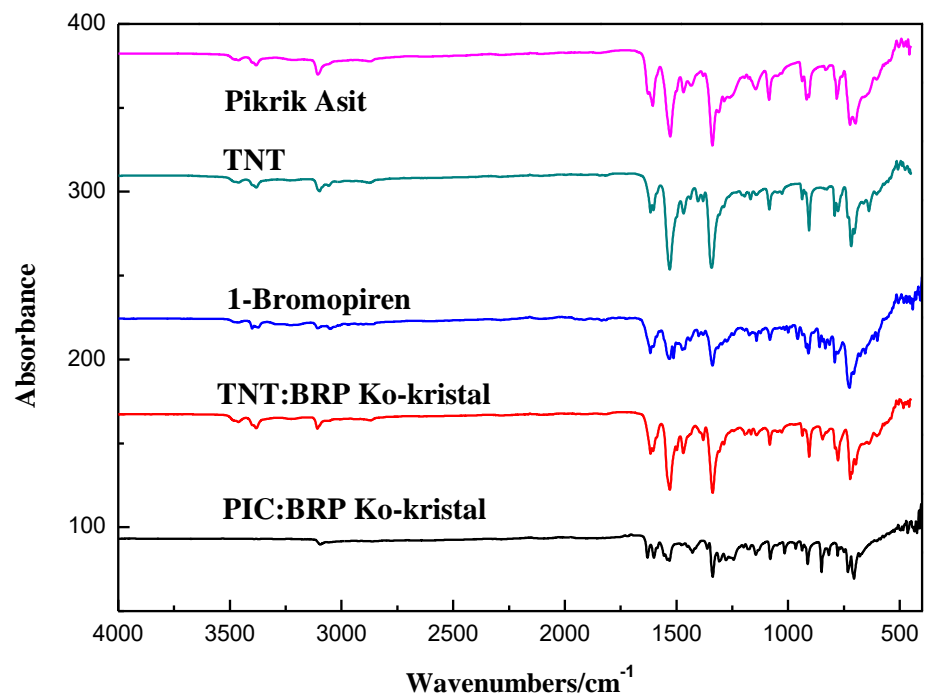

Şekil 6. Pikrik Asit, TNT, 1-Bromopiren, TNT: BRP ve PIC: BRP'nin kızılötesi spektrumlarının karşılaştırılması

\subsection{PIC:BRP ve TNT:BRP Ko-kristallerinin Diferansiyel Termal Analizi}

PIC: BRP ve TNT: BRP ko-kristallerinin diferansiyel termal analiz (a) ve termogravimetrik (b) eğrileri Şekil 7'te görülmektedir. Şekil 7(a)'da TNT: BRP kokristaline ait $117^{\circ} \mathrm{C}$ endotermik sinyali ve $298.2^{\circ} \mathrm{C}$ ekzotermik sinyali görülmektedir. TNT: BRP ko-kristalinin oluşumuyla yapı TNT (erime noktası $80.35^{\circ} \mathrm{C}$ ) ile karşılaştırıldığında termal olarak daha kararlı hale gelmiştir. PIC: BRP ko-kristalinin DSC eğrisi incelendiğinde üç $\left(117.2,144.4,174.3{ }^{\circ} \mathrm{C}\right)$ tane endotermik sinyal ve bir tane ekzotermik $\left(297.7^{\circ} \mathrm{C}\right)$ sinyal görülmektedir. İlk iki ekzotermik sinyalin pikrik asit (erime noktası $\left.121.8^{\circ} \mathrm{C}\right)$ ve 1-Bromopiren $\left(105^{\circ} \mathrm{C}\right)$ dan kaynaklandığı düşünülmektedir. 3. Ekzotermik sinyalin ise PIC:BRP ko-kristaline ait olduğu düşünülmektedir. Dolayısıyla ko-kristallenme reaksiyonu ile yeni oluşan ko-kristaller TNT ve Pikrik aside göre termal olarak daha kararlıdır. Şekil 7(b)'de PIC: BRP, TNT: BRP' nin kütle kaybı sirasıyla \%68.47, \%81.96 olarak ölçülmüştür. 


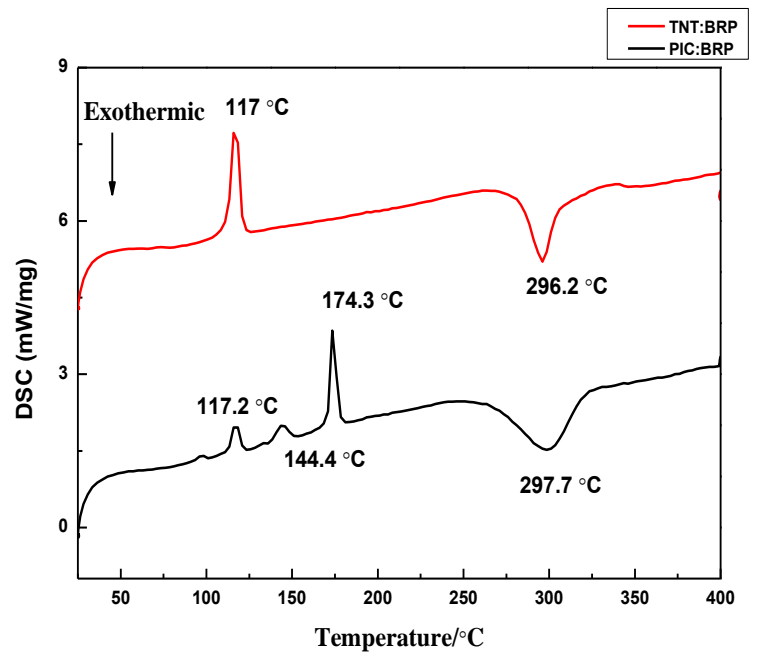

(a)

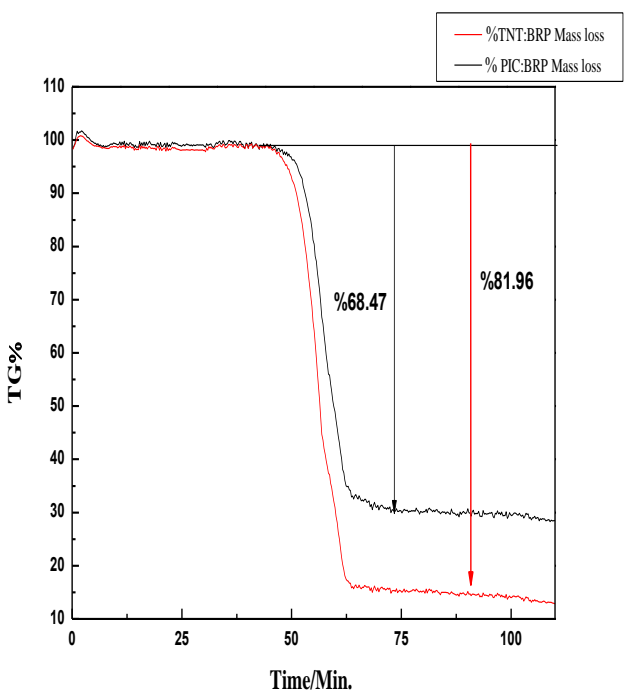

(b)

Şekil 7. PIC: BRP ve TNT: BRP için; (a) DSC eğrisi, (b) TG eğrisi

\subsection{Patlayıcı Performansı}

\subsubsection{Darbe Duyarlılı̆̆ı}

Pikrik Asit, TNT, PIC: BRP ve TNT: BRP için darbe duyarlılık testi sonuçları Şekil 8 'de gösterilmiştir. Pikrik asit, TNT, PIC: BRP ve TNT: BRP için h ho $_{5}$ değerleri sırasıyla $15.8 \mathrm{~cm}$ (darbe enerjisi $22.4 \mathrm{~J}), 25.1 \mathrm{~cm}(25.1 \mathrm{~J}), 70.8 \mathrm{~cm}(70.8 \mathrm{~J})$ ve $100 \mathrm{~cm}(100 \mathrm{~J})$ olarak ölcüldü. Darbe duyarlılığı büyük ölçüde maddelerin kimyasal ve fiziksel özelliklere bağlıdır. Yeni oluşan PIC: BRP ve TNT: BRP ko-kristallerinin darbe duyarlılıklarının artması yani darbe duyarlılığının iyileşmesi ko-kristal moleküller arasında oluşan kovalent olmayan etkileşimin ( $\pi \ldots \pi$ etkileşimi) bir sonucudur [20-22]. Ko-kristal moleküller arasındaki etkileşim ne kadar kuvvetli ise moleküller arasındaki sürtünme o oranda zorlaşacaktır. Bu sonuçlar, enerjik olmayan bir yardımcı maddeyle (1-Bromopiren) Pikrik asit ve TNT'nin ko-kristallendirilerek hassasiyeti önemli ölçüde iyileştirilmesinin mümkün olduğu anlamına gelir.

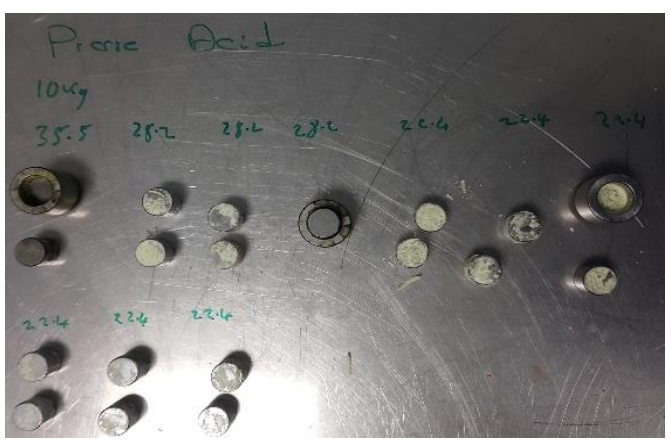

(a)

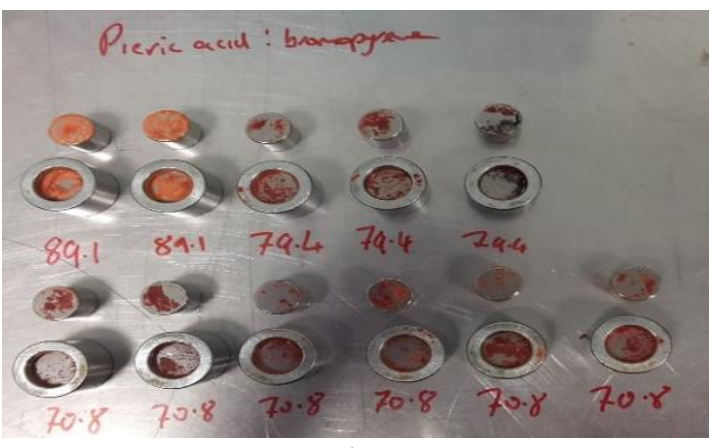

(b) 


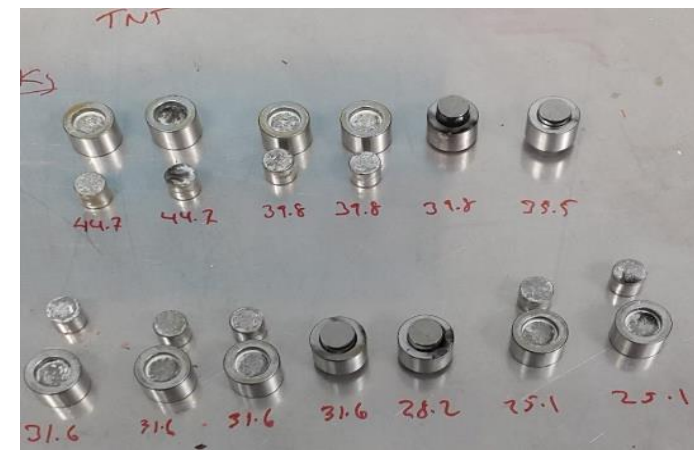

(c)

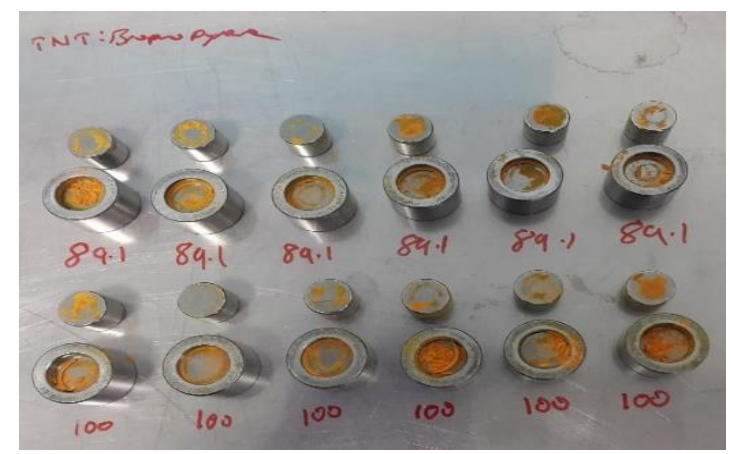

(d)

Şekil 8. BAM düşme çekiç cihazı ile ölçümler sonuçları (a) Pikrik asit, (b) PIC: BRP, (c) TNT, (d) TNT: BRP

\subsubsection{Patlama Performansının Hesaplanmast}

Patlama parametreleri, bir malzemenin enerjik performansını basit bir şekilde anlamak için çok önemlidir. Patlama performansı patlama basıncı ve patlama hızı olmak üzere iki önemli parametreden oluşmaktadır. $\mathrm{Bu}$ çalışmada, $\mathrm{C}_{\mathrm{a}} \mathrm{H}_{\mathrm{b}} \mathrm{O}_{\mathrm{c}} \mathrm{N}_{\mathrm{d}}$ (Pikrik Asit, TNT, PIC: BRP ve TNT: BRP)'nın patlama performansının belirlenmesinde Kamlet-Jacobs amprik denklemleri (2 ve 3) kullanılmıştır [37-39].

$\mathrm{D}=1.01 .\left(\mathrm{N}^{0.5}\right) \cdot\left(\mathrm{M}_{\text {ave. }} \mathrm{Q}\right)^{0.25} \cdot(1+1.30 . \rho)$

$\mathrm{P}=1.558 . \rho^{2}(\mathrm{~N}) .\left(\mathrm{M}_{\text {ave }} \mathrm{Q}\right)^{0.5}$

$\mathrm{D}$, patlama hızı $(\mathrm{km} / \mathrm{s}) ; \mathrm{P}$, patlama basıncı $(\mathrm{GPa}) ; \rho$, bileşiğin yoğunluğu $\left(\mathrm{g} / \mathrm{cm}^{3}\right) ; \mathrm{N}$, patlayıcı madde gramı başına gazlı patlama ürünleri molü; gaz halindeki ürünlerin ortalama moleküler ağırlığı (Q), patlamanın kimyasal enerjisi (kcal/g). Oluşum entalpileri $\left(\Delta \mathrm{H}^{\circ} \mathrm{f}\right)$, Gaussian 09 programı kullanılarak hesaplanmıştır. $\Delta \mathrm{H}^{\circ} \mathrm{f}$ katsayısı (0.239), kJ/mol'den kcal /mol'e dönüşüm faktörüdür. "M" bileşiğin moleküler ağırlığıdır $(\mathrm{g} / \mathrm{mol}) . \mathrm{N}, \mathrm{M}_{\mathrm{ave}}$ ve $\mathrm{Q}$ parametreleri, literatürde açıklandığı gibi her patlayıcının kimyasal bileşimine göre hesaplanmaktadır (Tablo 3) [40].

Tablo 3. $\mathrm{C}_{\mathrm{a}} \mathrm{H}_{\mathrm{b}} \mathrm{O}_{\mathrm{c}} \mathrm{N}_{\mathrm{d}}$ patlayıcılarının $\mathrm{N}, \mathrm{M}_{\mathrm{ave}}$ ve Q parametrelerinin hesaplanmas1 [40]

\begin{tabular}{cccc}
\hline \multicolumn{4}{c}{ Stokiyometrik ilișkiler } \\
\hline $\begin{array}{c}\text { Parametre } \\
\mathrm{N}\end{array}$ & $\mathrm{c} \geq 2 \mathrm{a}+\mathrm{b} / 2$ & $2 \mathrm{a}+\mathrm{b}>/ 2 \mathrm{c} \geq \mathrm{b} / 2$ & $\mathrm{~b} / 2>\mathrm{c}$ \\
$\mathrm{M}_{\text {ave }}$ & $(\mathrm{b}+2 \mathrm{c}+2 \mathrm{~d}) / 4 \mathrm{M}$ & $(\mathrm{b}+2 \mathrm{c}+2 \mathrm{~d}) / 4 \mathrm{M}$ & $(\mathrm{b}+\mathrm{d}) / 2 \mathrm{M}$ \\
& $4 \mathrm{M} /(\mathrm{b}+2 \mathrm{c}+2 \mathrm{~d})$ & $(56 \mathrm{~d}+88 \mathrm{c}-8 \mathrm{~b}) /(\mathrm{b}+2 \mathrm{c}+2 \mathrm{~d})$ & $(2 \mathrm{~b}+28 \mathrm{~d}+32 \mathrm{c}) /(\mathrm{b}+\mathrm{d})$ \\
$\mathrm{Q} \times 10^{-3}$ & $\left(28.8 \mathrm{~b}+94.05 \mathrm{a}+0.239 \Delta \mathrm{H}^{\circ} \mathrm{f}\right) / \mathrm{M}$ & {$[28.9 \mathrm{~b}+94.05(\mathrm{c} / 2-$} & $\left(57.8 \mathrm{c}+0.239 \Delta \mathrm{H}^{\circ} \mathrm{f}\right) / \mathrm{M}$ \\
\hline
\end{tabular}

$\mathrm{C}_{\mathrm{a}} \mathrm{H}_{\mathrm{b}} \mathrm{O}_{\mathrm{c}} \mathrm{N}_{\mathrm{d}}$ tipi patlayıcı için, oksijen dengesi ( $\Omega$ ) literature göre hesaplanmıştır [41]. Hesaplanan oksijen dengesi $(\Omega)$, standart oluşum 1sıs1 $\left(\Delta \mathrm{H}^{\circ} \mathrm{f}\right)$, patlama $(\mathrm{Q})$ kimyasal enerjisi, yoğunluk $(\rho)$, patlama hızı (D) ve basınç (P) değerleri Tablo 4'de listelenmiştir.

Tablo 4. Hesaplanan Patlayıcı performansı parametreleri

\begin{tabular}{ccccccc}
\hline Maddeler & $\Omega(\%)$ & $\Delta \mathrm{H}^{\circ} \mathrm{f}\left(\mathrm{kj} \cdot \mathrm{mol}^{-1}\right)$ & $\begin{array}{c}\mathrm{Q} \\
(\mathrm{kcal.g})\end{array}$ & $\begin{array}{c}\rho \\
\left(\mathrm{g} . \mathrm{cm}^{-3}\right)\end{array}$ & $\begin{array}{c}\mathrm{D} \\
\left(\mathrm{km} \cdot \mathrm{s}^{-1}\right)\end{array}$ & $\begin{array}{c}\mathrm{P} / \\
\mathrm{GPa}\end{array}$ \\
\hline PIC:BRP & -135 & -50.78 & 748 & 1.85 & 4.85 & 10.62 \\
Pikrik & -45 & -130.76 & 6168.67 & 1.81 & 7.87 & 28.28 \\
Asit & -73 & 50.57 & 1400.5 & 1.64 & 7.11 & 19.01 \\
TNT & 91.01 & 725.1 & 1.69 & 4.45 & 8.46 \\
\hline TNT:BRP & -148 & &
\end{tabular}


TNT ve Pikrik asit' in patlaması esnasında ortamda enerjik olmayan 1-Bromopiren bulunduğu için TNT ve Pikrik asit' in patlama hızı ve patlama basıncı azalmaktadır. Tablo 4'de verilen patlama basinc1 ve patlama hizı enerjik maddenin patlama tepkimesinin oksijen dengesi $(\Omega)$ kurallarına göre patladığı varsayılarak ve hesaplanan teorik formasyon entalpisi kullanılarak elde edilen patlama entalpisi gaz ürünler göz önüne alınarak yapılan hesaplanmış değerlerdir [42]. Ancak, 1-Bromopiren oksijen ve azot içermez, karalı bir halkalı yapıdır, bu sebepten $(\Omega)$ kuralları geçerlide olsa patlamaya bir katkıda bulunmaz. Bu durumdan dolayı patlama sadece TNT ve Pikrik asittin gerçekleştirdiği bir iç tepkime sonucu oluşmaktadır. PIC: BRP ve TNT: BRP kokristallerin' de yer alan 1-Bromopiren patlamaya katkıda bulunmadığından patlama basıncını ve hızını düşürmektedir.

\section{Sonuç ve Yorum}

Pikrik asit ile 1-Bromopiren ve TNT ile 1-Bromopiren 1: 1 molar oranında hazırlanarak yeni bir enerjik ko-kristal başarıyla sentezlendi ve karakterize edildi. Tek kristal X 1şını kırınım sonuçlarına göre, PIC: BRP ve TNT: BRP ko-kristalleri elektron verici-elektron alıcı $\pi \ldots \pi$ istifleme etkileşimleri sonucu oluşmaktadır. Ko-kristallenme yöntemiyle yeni oluşan enerjik maddelerin fiziksel ve kimyasal özellikleri tamamıyla değişmiştir. Ayrıca kovalent olmayan etkileşimler $(\pi \ldots \pi$ istifleme) Pikrik asit ve TNT enerjik maddelerin hassasiyetinde önemli derecede değişiklik meydana getirmiş ve yeni oluşan ko-kristaller hassas (duyarsız) olarak enerjik madde sınıfında kullanılabilirler. Termal analizler sonucu yeni elde edilen ko-kristaller TNT ve Pikrik asit'be göre termal olarak daha kararlıdır. Bu detaylı çalışma sonucu ile yoğunluk, oksijen dengesi, erime noktası, ayrışma sıcaklığı, patlama performansı (hız, basınç) gibi önemli fiziksel ve kimyasal özelliklerin ko-kristallenme yöntemiyle değiştiğini ortaya koymaktadır. TNT ve Pikrik asit' in patlaması esnasında ortamda enerjik olmayan 1-Bromopiren bulunduğu için TNT ve Pikrik asit' in patlama hızı ve patlama basıncı kısmi olarak azalmaktadır. 1Bromopiren oksijen ve azot içermez, karalı bir halkalı yapıdır, bu sebepten $(\Omega)$ kuralları geçerlide olsa patlamaya bir katkıda bulunmaz. PIC: BRP ve TNT: BRP ko-kristallerin' de yer alan 1-Bromopiren patlamaya katkıda bulunmadığından teorik hesaplamalardan da görüldüğü gibi patlama basıncını ve hızını düşürmektedir. Yapılan bu çalışmayla; sivil ve askeri amaçlı patlayıcı madde uygulamalarında kullanılabilecek maddenin iyileştirilmiş fiziksel ve kimyasal özelliklere sahip, termal olarak kararlı özelliklere sahip, düşük hassasiyete sahip; yani sürtünme, şok, 1s1 gibi istenmeyen dış etkilere maruz kaldığında kolayca infilak etmeyen, uzun süreli depolanabilen yeni nesil alternatif enerjik maddeler sentezlenmiştir.

\section{Teşekkür}

Dr. Nilgün ŞEN; TÜBİTAK-BIDEB 2219-Uluslararası Doktora Sonrası Araştırma Burs Programına projeye maddi destek sağladığı, Prof. Colin R. Pulham'a bu proje boyunca desteklerinden dolayı, Dr. Gary Nichol'a Edinburgh Üniversitesi'ndeki X-1şını servis bölümünde tek kristalli veri topladığı için, son olarak Cambridge Üniversitesi Cavendish Laboratuar ekibine Darbe duyarlılığı testi için BAM cihazını kullanmaya erişim iznini verdiği için teşekkürü bir borç bilirim.

\section{Kaynakça}

[1] A. Becuwe, A. Delclos, "Low-sensitivity explosive compounds for low vulnerability warheads.", Propell. Explos. Pyrotech., 18(1), 1-10, 1993.

[2] A. Zhurova, V. V. Zhurov and A. A. Pinkerton, " Structure and Bonding in $\beta$-HMX-Characterization of a Trans-Annular N...N Interaction.”, JACS, 129(45), 13887-13893, 2007. 
[3] H. Östmark, S. Wallin, and P. Goede," High energy density materials (HEDM): overview, theory and synthetic efforts at FOI.", CEJEM, 4(1-2), 83-108, 2007.

[4] T. Klapötke, C. Janiak, and R. Alsfasser, Moderne Anorganische Chemie, Berlin:Walter de Gruyter, 2007.

[5] R. P. Singh, R. D. Verma, D. T. Meshri, J. N. M. Shreeve, "Energetic nitrogen-rich salts and ionic liquids." Angew. Chem., 45(22), 3584-3601, 2006.

[6] T. M. Klapötke, "New nitrogen-rich high explosives", High Energy Density Materials, Springer, Berlin: Heidelberg, 2007, pp. 85-121.

[7] K. B. Landenberger, "Cocrystallization of Energetic Materials", PhD thesis, The Univ. of Michigan, Michigan, USA, 2013.

[8] M. Jaidann, S. Roy, H. Abou-Rachid and L. S. Lussier, "A DFT theoretical study of heats of formation and detonation properties of nitrogen-rich explosives”, J. Hazard. Mater., 176(1-3), 165$173,2010$.

[9] T. Clark, M. Hennemann, J. S. Murray, P. Politzer, "Halogen bonding: the $\sigma$-hole", J. Mol. Model, 13, 291-296, 2007.

[10] P. Politzer, J. S. Murray, J. M. Seminerio, P. Lane, M. E. Grice, M. C. Concha, "Computational characterization of energetic materials", J. Mol Struc-Theochem, 573(1-3), 1-10, 2001.

[11] L. Türker, T. Atalar, S. Gümüş, Y. Çamur, "A DFT study on nitrotriazines”, J. Hazard. Mater., 167(1-3), 440-448, 2009.

[12] M.D. Perera, "Hydrogen and halogen bonding in co-crystallization: from fundamentals to applications", PhD thesis, Dept. of Chemistry, Kansas State Univ., Kansas, USA, 2017.

[13] K. B. Landenberger, O. Bolton, and A.J. Matzger, "Energetic-energetic cocrystals of diacetone diperoxide (DADP): Dramatic and divergent sensitivity modifications via cocrystallization.", JACS, 137(15), 5074-5079, 2015.

[14] E. Arunan, G. R. Desiraju, R. A. Klein, J. Sadlej, S. Scheiner, I. Alkorta, D. C. Clary, R. H. Crabtree, J. J. Dannenberg, P. Hobza, H. G. Kjaergaard, A. C. Legon, B. Mennucci and D. J. Nesbitt, "Definition of the hydrogen bond (IUPAC Recommendations 2011)", Pure Appl. Chem., 83(8), 1637-1641, 2011.

[15] R. Berger, G. Resnati, P. Metrangolo, E. Weber and J. Hulliger, "Organic fluorine compounds: a great opportunity for enhanced materials properties.”, Chem. Soc. Rev., 40(7), 3496-3508, 2011.

[16] J. P. Lommerse, A. J. Stone, R. Taylor and F. H. Allen, "The nature and geometry of intermolecular interactions between halogens and oxygen or nitrogen.”, JACS, 118(13), 3108-3116, 1996.

[17] T. F. Headen, C. A. Howard, N. T. Skipper, M. A. Wilkinson, D. T. Bowron and A. K. Soper, "Structure of $\pi-\pi$ Interactions in Aromatic Liquids.", JACS, 132(16), 5735-5742, 2010.

[18] J. C. Barnes and W. Golnazarians, "The 1: 1 complex of pyrene with 2, 4, 6-trinitrotoluene." Acta Crystallogr C Struct Chem., 43(3), 549-552, 1987.

[19] O. Bolton and A. J. Matzger, A. J., "Improved stability and smart-material functionality realized in an energetic cocrystal.”, Angew. Chem., 50(38), 8960-8963, 2011.

[20] N. Şen, "N. Characterization and properties of a new energetic co-crystal composed of trinitrotoluene and 2, 6-diaminotoluene", J. Mol Struct., 1179, 53-461, 2019.

[21] N. Şen, "A new cocrystal explosive trinitrotoluene (TNT): 1-amino-4-bromonaphthalene with reduced sensitivity." Turk. J. Chem., 42(5), 1321-1333, 2018.

[22] N. Şen, “A 1: 1 energetic co-crystal formed between trinitrotoluene and 2, 3-diaminotoluene.", Maced. J. Chem. Chem. En., 37(1), 61-69, 2018.

[23] J. Ledgard, "The Preparatory Manual of Explosives.", 3rd ed., Seattle, Washington USA, 2007, pp. 180.

[24] O. V. Dolomanov, L. J. Bourhis, R. J. Gildea, J. A. K.Howard, H. Puschmann, “OLEX2: A complete structure solution, refinement and analysis program.”, J. Appl. Crystallogr., 42(2), 339-341, 2009.

[25] G. M. Sheldrick, "Crystal structure refinement with SHELXL.", Acta Crystallogr C Struct Chem, A71(1), 3-8, 2015.

[26] G. M. Sheldrick, "Crystal structure refinement with SHELXL.”, Acta Crystallogr C Struct Chem, C71, 3-8, 2015.

[27] K. L. Kosanke, B. T. Sturman, R. M. Winokur and B. J. Kosanke, "Encyclopedic Dictionary of Pyrotechnics:(and related subjects).", Journal of Pyrotechnics, Whitewear, CO, USA, 2012.

[28] C. D. Fuh, J. S. Lee and C. M. Liaw, "The design aspect of the bruceton test for pyrotechnics sensitivity analysis.", JDS, 1(1), 83-101, 2003.

[29] Gaussian 09, Revision B.01. M. J. Frisch, G. W. Trucks, H. B. Schlegel, G. E. Scuseria, M. A. Robb, J. R. Cheeseman, G. Scalmani, V. Barone, B. Mennucci, G. A. Petersson, H. Nakatsuji, M. Caricato, X Li, H. P. Hratchian, A. F. Izmaylov, J. Bloino, G. Zheng, J. L.Sonnenberg, M. Hada, M. Ehara, K. Toyota, R. Fukuda, J. Hasegawa, M. Ishida,T. Nakajima, Y. Honda, O. Kitao, H. Nakai, T. Vreven, J. A. Montgomery, Jr., J. E.Peralta, F. Ogliaro, M. Bearpark, J. J. Heyd, E. Brothers, K. N. Kudin, V. 
N. Staroverov, R. Kobayashi, J. Normand, K. Raghavachari, A. Rendell, J. C. Burant, S. S. Iyengar, J. Tomasi, M. Cossi, N. Rega, N. J. Millam, M. Klene, J. E. Knox, J. B. Cross, V. Bakken, C. Adamo, J. Jaramillo, R. Gomperts, R. E. Stratmann, O. Yazyev, A. J. Austin, R. Cammi, C. Pomelli, J. W. Ochterski, R. L. Martin, K. Morokuma, V. G. Zakrzewski, G. A. Voth, P. Salvador, J. J. Dannenberg, S. Dapprich, A. D. Daniels, Ö. Farkas, J. B. Foresman, J. V. Ortiz, J. Cioslowski, and D. J. Fox,., Wallingford, CT: Gaussian Inc., 2009.

[30] R. Dennington, T. A. Keith and J. Millam, GaussView, Version 5, Semichem Inc., Wallingford, CT, 2009.

[31] L.A. Curtiss, K. Raghavachari, P. C. Redfern and J.A. Pople, “Assessment of Gaussian-2 and density functional theories for the computation of enthalpies of formation.”, J. Chem. Phys., 106, 1063-1079, 1997.

[32] E. F. C. Byrd and B. M. Rice, "Improved prediction of heats of formation of energetic materials using quantum mechanical calculations.”, J. Chem. Phys., A113, 5813-5813, 2009.

[33] B. M. Rice, S. V. Pai and J. Hare, "Predicting heats of formation of energetic materials quantum mechanical calculations.”, Combus. Flame, 118, 445-458, 1999.

[34] P. J. Linstrom and W. G. Mallard, "NIST Standard Reference Database Number 69.", National Institute of Standards and Technology, Gaithersburg, MD, USA, 2005.

[35] K. Molčanov, I. Sabjić and B. Kojić-Prodić, "Face-to-face $\pi$-stacking in the multicomponent crystals of chloranilic acid, alkali hydrogenchloranilates, and water.", Cryst. Eng. Comm., 13, 4211-4217, 2011.

[36] H.H. Freedmann, "Intramolecular H-bonds. I. A spectroscopic study of the hydrogen bond between hydroxyl and nitrogen.”, JACS, 83, 2900-2905, 1961.

[37] M. J. Kamlet and S. F. Jacobs, "Chemistry of detonations I. A simple method for calculating detonation properties of C-H-N-O explosives.”, J. Chem. Phys., 48, 23-25, 1968.

[38] M. J. Kamlet and J. E. Ablard, "Chemistry of detonations. II. Buffered equilibria.", J.Chem. Phys., 48(1), 36-42, 1968.

[39] M. J. Kamlet and C. J. Dickenson, "Chemistry of detonations. III. Evaluation of the simplified calculation method for Chapman-Jouguet detonation pressures on the basis of available experimental information.", J.Chem. Phys., 48(1), 43-51, 1968.

[40] L. Qiu, H. Xiao, X. Gong, X. Ju and W. Zhu, "Theoretical studies on the structures, thermodynamic properties, detonation properties, and pyrolysis mechanisms of spiro nitramines.", J Phys Chem Biophys., 110(10),3797-3807, 2006.

[41] M. J. Kamlet, H. G. Adolph, "The relationship of Impact Sensitivity with Structure of Organic High Explosives. II. Polynitroaromatic explosives”, Propell. Explos. Pyrotech, 4, 30-34, 1979

[42] T.M. Klapötke, Chemistry of High-Energy Materials, Walter de Gruyter, 2011, p:75-76.

\section{EKLER}

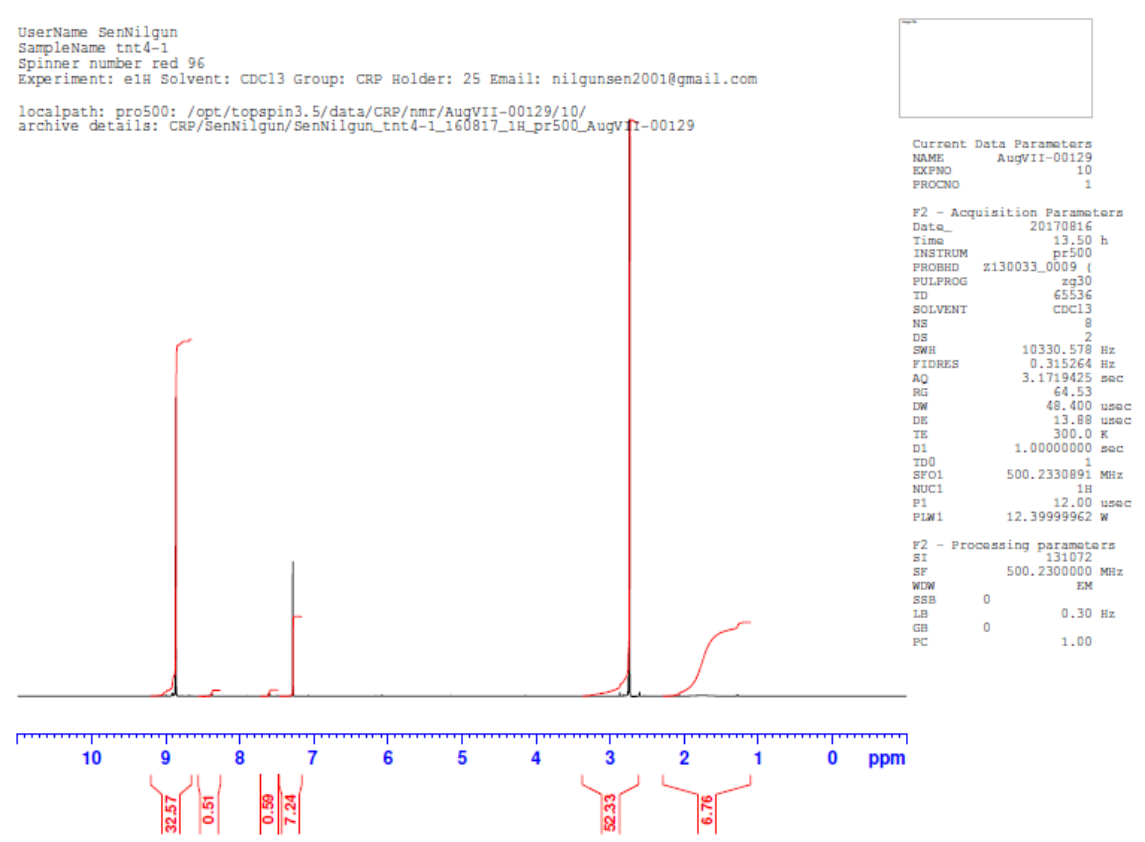

Şekil E1. TNT ${ }^{1} \mathrm{H}-\mathrm{NMR}$ spekturumu 


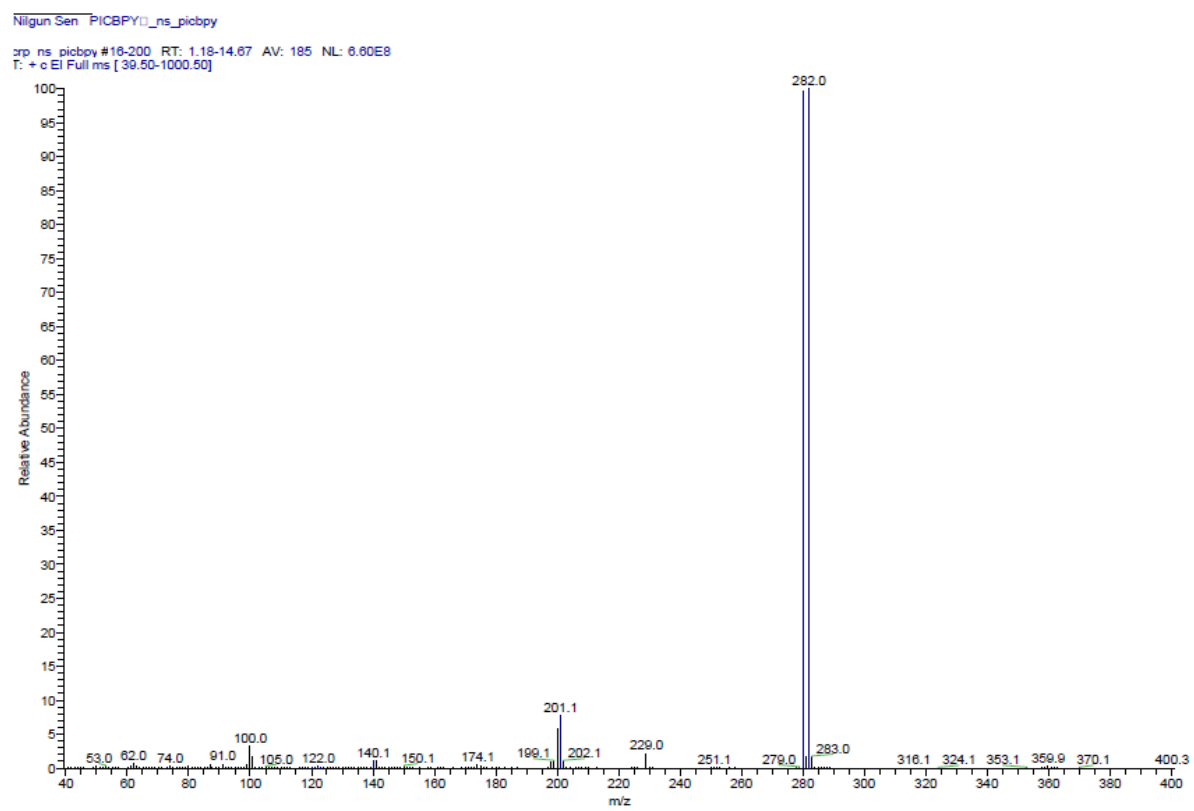

Şekil E2. PIC:BRP ko-kristalinin MS spekturumu

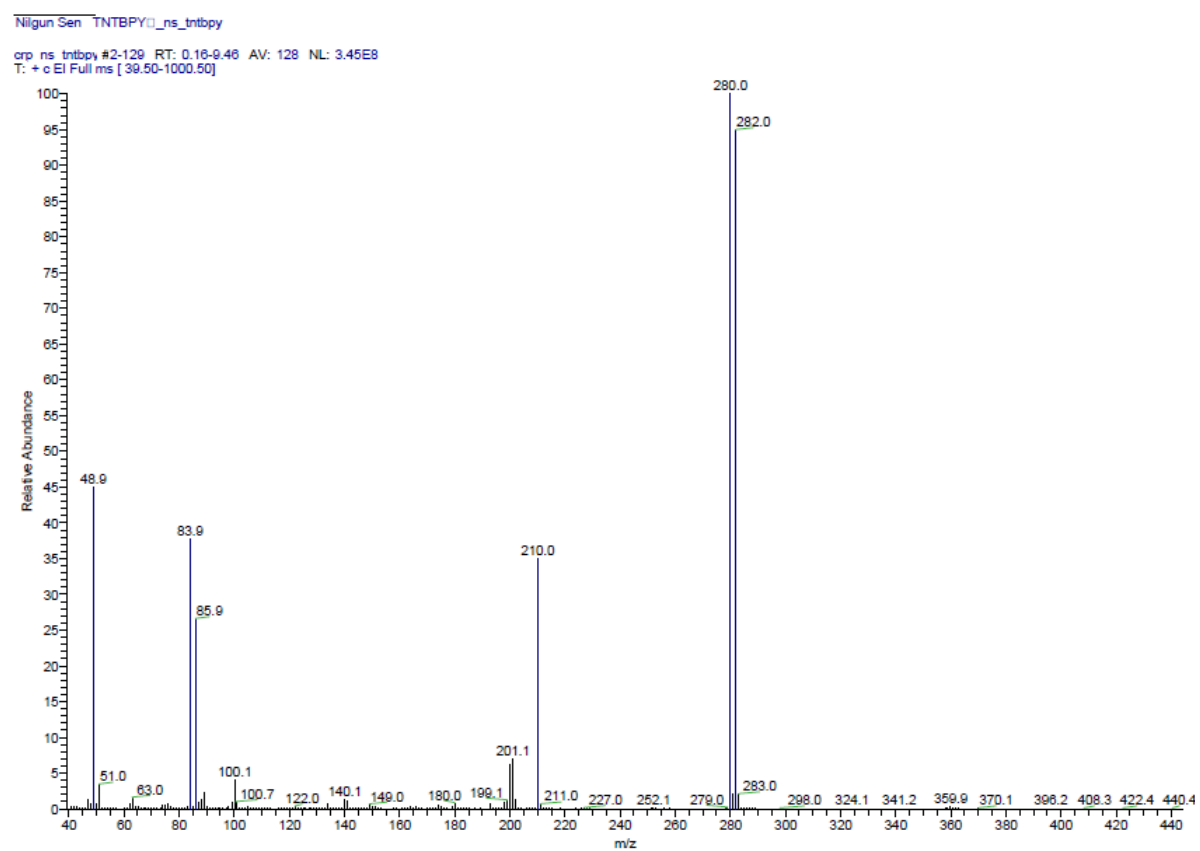

Şekil E3. TNT:BRP ko-kristalinin MS spekturumu 